\title{
Ecological Study of Harra Forests in the Nayband Protected Area at Bushehr Province, Iran
}

\section{Reza E Owfi*}

Department of Rangeland Management, Sari Agricultural Sciences and Natural Resources University, Sari, Iran

\begin{abstract}
The protected area of Nayband is located at 320 kilometres southeast of Bushehr Province and that is of particular interest due to its unique ecosystem. The specific plant species of the region is Harra (scientific name: Avicennia marina) of Verbenaceae family which is a kind of tree of the mangrove plants and represent specific ecosystems in the tropics and it is result of accumulation of very special flora and fauna in the coastal deltas and rivers and bays where they are exposed to permanent tides. With an area of 390 hectares, this area of mangrove forests is the largest remaining mangrove forests in longitude above 27 degrees in South West Asia in terms of dense community. This paper deals with ecological mangrove forests. The related data were collected and then the area was visited to evaluate the circumstances of the ecosystem. Next, the related data were extracted and combined and finally some suggestions are offered for improving ecosystem.
\end{abstract}

Keywords: Harra; Nayband; Mangrove; Avicennia marina

\section{Introduction}

The Nayband protected area is located at geographical location of $52^{\circ} 38^{\prime}$ East and $27^{\circ} 22^{\prime}$ North in 320 kilometers southeast of Bushehr Province. The region has 22,500 hectares and was registered as a protected area in 1978. In 2004, this area, along with other regions around the part of the Persian Gulf was registered as the first National Marine Park and then it was announced that the total are is 49815 hectares [1].

In terms of natural landscape, this area includes numerous estuaries, mangrove forests, deep valleys as well as rocky and sandy beaches. Diversity of wild animals and mammals is unique in this area. In addition, there are many types of amphibians and birds in the region that are so dependent on these ecosystems. There are different plant species in the area which majority of these plants are halophytes and can be seen in the offshore areas.

Aquatic plants are available in coastal areas too. However, what is important is Harra ecosystem as a particular nature which has the greatest effect on the ecosystem; so that no any plant species are able to compete with it (Figure 1).

\section{Research Methodology}

The following steps were taken for the purpose of paper:

1) Collecting data: Given that the area and species are unique, so the other researchers conducted in other similar places are not generalizable in current paper. Hence, some research resources have been used exclusively in this area and the species. Natural Resources and Environment departments and universities especially the Hormozgan University are among the listed research investigations in this area.

2) Presence in the region: To identify and precisely evaluate circumstances of the ecosystem.

3) Extract the desired and key data: At this point, the desired and key data are extracted and integrated from all the gathered data.

4) Suggestions: Some suggestions are offered to improve ecosystem according to information obtained from aforementioned steps.

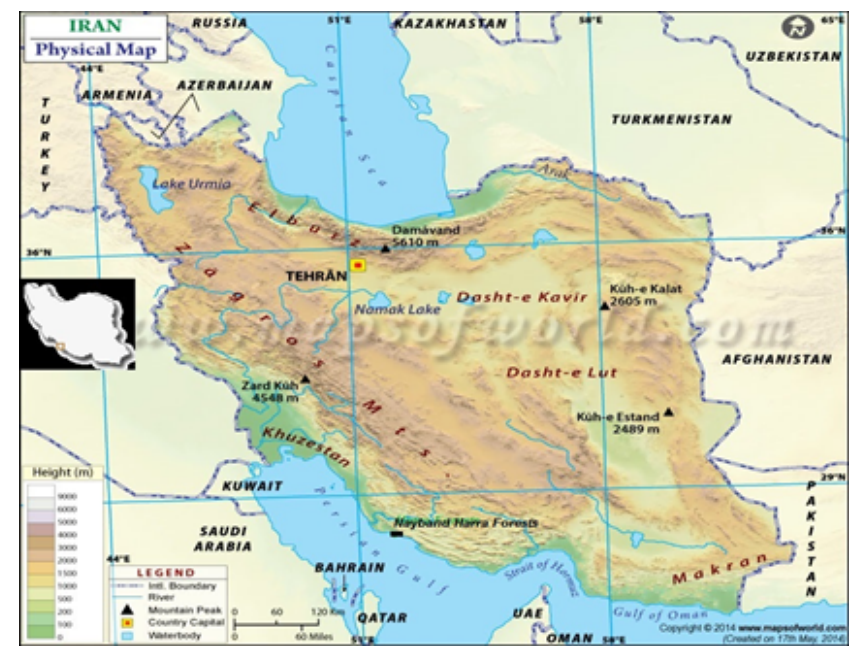

Figure 1: The location of area in the country.

\section{Results}

In this regard, remarkable points are:

\section{Climate}

The area is located in hot and humid climate with high absolute humidity. A district with adverse weather situations which is characterized by minimal rainfall, water vapor, a high absolute

*Corresponding author: Reza E Owfi, Faculty of Natural Resources, Department of Rangeland Management, Sari Agricultural Sciences and Natural Resources University, Sari, Iran, Tel: 00989171120831; E-mail: owfireza@yahoo.com

Received November 02, 2017; Accepted January 17, 2018; Published January 25, 2018

Citation: Owfi RE (2018) Ecological Study of Harra Forests in the Nayband Protected Area at Bushehr Province, Iran. J Coast Zone Manag 21: 454. doi: 10.4172/2473-3350.1000454

Copyright: (c) 2018 Owfi RE. This is an open-access article distributed under the terms of the Creative Commons Attribution License, which permits unrestricted use, distribution, and reproduction in any medium, provided the original author and source are credited. 
humidity, intensive solar radiation and frequency of dust. Generally, these areas possess an annual rainfall of up to 150 millimeters with the average annual temperature $25^{\circ} \mathrm{C}[2-5]$.

\section{Soil}

These plants are located in areas that are under permanent tide. Normally, soil in this area is somewhat sediment, granulated, submergence and salty.

\section{Topography}

The area includes a set of small islands that are located in the clay hills, tidal sludge fields and shallow estuaries.

\section{Water}

In these ecosystems, water possess highest quality in terms of food and physicochemical properties and tide plays an important role in this regard; which causes displacement of water from the sea to the ecosystem and reversed so it adjusts the salinity. However, Harra plants are capable to take the salt in water and then store it. This also reduces the salinity of the water [6].

\section{Organism}

In this section, we examine organisms in two groups as plants and animals:

Plants: Nayband vegetation including Harra and other aquatic plants such as seagrass and algae communities in coastal ecosystems and also halophyte plants such as Tamarix sp, Salsola rigida, Alhagi camelorum and Limonium sp in offshore areas. Ziziphus sp, Prosopis sp, Ficus religiosa, Tecomella undulata, Calotropis procera, Zygophyllum Eurypterum, Daphne sp and Aloe Littoralis are among other plant species in the mountains and high plains. However, Harra can be considering as the most important and most characteristic species in this area which is discussed in details in the following.

Morphology and physiology of Harra plants: Hara has oval leaves with narrow base. The leaves are green and shiny on surface and the rear surface is in white or gray. The length is 5 to 7 centimeters and it has an oval-shaped fruit. It also has small yellowish- golden blossoms and has four petals with length of a few millimeters. Harra has a short and shallow root with considerable lateral roots which gradually cover around the tree and form a grid-shape pattern. Therefore, it continues to live in such marshy environment. These plants, however, produce pneumatophore roots in flooding conditions which make both respiration in anaerobic environment and plant establishment possible in this unstable fields. The roots have corky texture trough which provide the necessary oxygen in anaerobic conditions [7]. These roots have valves which only allow air circulates into the plant. As mentioned, these plants have the ability to resist against salt water around the roots and using semi-permeability properties of the roots to prevent the entry of salt. Then, repulse entered salt into the plant using special salt glands on their leaves. The leaves have been osmotic pressure of 30 to 35 atmospheres which allow only fresh water get through the roots. Alternatively, additional salts are accumulated in old and falling leaves. Normally during a day, 0.2 to 0.35 milligrams of salt excreted from every five square centimeters of their leaves. The plants have a height of 3 to 6 meters with multiple trunks. They are considered as evergreen plants. Their flowering time is July to August [8].

Seeds grow on the mother tree and consequently, produce seedlings. The seedlings are then separated from the tree and fall into the water. Their reproductive method is like semi-vivipar [9].
The ecological structure of Harra plants: Harra forests ground is composed of two parts, one of which is occupied by the root systems and so-called hard subsurface and other one is muddy pans and so-called soft subsurface. In each of these two sectors, there are special marine organisms; such as molluscs, crustaceans and fishes. Upon entering the ecosystem, some species like shrimp such as pink shrimp and crustaceans such as mudskippers begin to dig in the ground and therefore create a safe place for their larvaes, in addition to help better ventilation. Tide also carries required nutrients from the sea to the ecosystem. In addition, Harra plants act as crushers and natural protection for banks. Given to two tides a day, provide specific environmental conditions to maritime forest. These plants need 20 to 32 units per thousand salinity for proper growth. However, they are not able to withstand at temperatures below $5^{\circ} \mathrm{C}$. Harra plants are optional halophyte so they have low resistance to salinity in dry condition. Due to competition with other flowering plants, Harra plants have adapted to live in tidal areas and such an environment. Harra plants involve in a highly complex food chain and are dependent in detritivore system [2]

Health benefits, industrial applications and local use of Harra plants: Harra leaves can be effective on mycobacterium leprae that is cause of leprocy. Syrup within its vessels is also useful on ichthyosis. Its roots are used to increase sexuality. The immature seeds can be used as a poultice to treat infected wounds and burns. In industry, it is also use for the production of Tannic. In rural communities in the region, the plants are used as cellulose fuel source which has a heating value of 4,000 kilocalories per kilogram. The branches are used for feeding livestock, especially camels. The wood of trees are also used for construction and building as they are resistant to Termite attack [10].

Animals: This ecosystem is home to a variety of animals; including migratory and native birds such as kingfishers, herons, storks, pelicans, flamingos and duck, either immigrant only in winter or locally they have a permanent presence in the region. Leopard, goat, wolf, jackal, rabbit, fox and ram are among the mammals in the ecosystem. Dolphin and whale are also among marine mammals which can be found in the high seas and deep ecosystems. Diverse and plenty of fish are also found in this ecosystem. Hawksbill sea turtle and green sea turtle are the most important and unique amphibian of the area [11].

\section{Discussion and Conclusion}

1) Biodiversity and species in the region is considerable that it adds to the importance of this ecosystem.

2) Most of the uniqueness of the whole ecosystem relates to Harra species; so that the loss or weakening it would change the nature of the ecosystem.

3) Overall, no species are not able to compete with Harra plant so it consider as the dominant plant species in the region.

4) Development, production and promotion of ecotourism could be an important parameter for employment in the region.

5) According to similar ecologic properties in other parts of the province, can take necessary actions to extent Harra plant and similar forests in other parts; which sought cooperation of the relevant government agencies.

6) Given the heavy reliance of animals to Harra forests, conservation and development of species should be in the first property.

7) Given to exploiting Harra plants for purposes such as construction industry, fuel and livestock feed by natives, alternative 
Citation: Owfi RE (2018) Ecological Study of Harra Forests in the Nayband Protected Area at Bushehr Province, Iran. J Coast Zone Manag 21: 454. doi: $10.4172 / 2473-3350.1000454$

Page 3 of 3

Sources should be used to protect these valuable species.

8) In recent years, the main factors threatening Harra forest ecosystem includes road constructing, restricting tide entries to the estuary, industrial extensive activities in adjacent areas and consequently, the pollution discharged into the sea, overfishing in the area, unloading ships' tank into the sea and seismic operations for oil and gas discoveries in the region. In this regard, all the relevant bodies should take action to improve the ecosystem.

\section{References}

1. Safiari S (2005) Mangrove forests. Forests and Rangelands. Society press, Vermont. P. 564.

2. Kelletat $D(2000)$ Physical geography of the seas and coasts.

3. Mobin S (1981) Plant geography. Tehran University Press, Iran. p. 271.
4. Mobin S (1978) Vegetations of Iran. Tehran University Press, Iran. p. 958.

5. Mozaffarian V (1996) A dictionary of Iranian plant names. Farhang Moaser Press, Tehran. p. 740.

6. Ramazani GB (2007) Course notes of biogeography (Gulf ecosystems). Rasht Azad University, Iran. p. 43.

7. Sabeti H (1967) Iran forests. Franklin press, Franklin. p. 247.

8. Sabeti H (2002) Iran forests, trees and shrubs. Yazd University Press, Yazd. p. 786.

9. Basra AS, Basra RK (2000) Mechanisms of environmental stress resistance in plants. Ferdowsi University Press, Iran. p: 467

10. Omid BR (2000) Approaches to producing and processing of medicinal plants. Astan Quds Razavi Press, Iran. p. 1103.

11. Zargari A (2014) Medicinal plants. Tehran University Press, Iran. p. 4274. 